\title{
ANALISIS CITRA DIGITAL SAMPEL TANAH DAN BATUAN MENGGUNAKAN MICRO-CT SKYSCAN 1173
}

\author{
Rizki Fahmi Sumaryono ${ }^{1, \text { a) }}$, Aceng Kurnia Rochmatulloh ${ }^{1)}$, \\ Ulpa Zein Fawziah ${ }^{1)}$, Selly Feranie ${ }^{1)}$, Fourier D.E Latief ${ }^{2)}$ \\ ${ }^{1}$ Departemen Pendidikan Fisika FPMIPA UPI, Jl.Dr Setiabudhi No.229, Bandung 40154 \\ ${ }^{2}$ Fisika Bumi dan Sistem Kompleks FMIPA ITB, Jl. Ganesha No. 10 Bandung 40132 \\ Email: a)fahmisumaryono@gmail.com, ${ }^{\text {b) }}$ dzareljabbar@gmail.com
}

\begin{abstract}
Abstrak
Teknologi pencitraan struktur 3D medium berpori berkembang pesat dengan adanya perangkat pemindai X-Ray Micro Computed Tomography (Micro-CT Scan). Pada penelitian ini dilakukan analisis citra digital sampel tanah dan batuan hasil pemindaian dengan Micro-CT Skyscan 1173. Analisis lanjutan dilakukan pada sampel tanah yang dipindai dengan dua parameter energi sinar-X yang berbeda $(100 \mathrm{kV}$ dan $130 \mathrm{kV}$ ). Analisis berikutnya berfokus pada perbandingan parameter fisis sampel tanah dan batuan. Sampel digital tanah dan batuan masing-masing berukuran $560 \times 560 \times 475$ piksel dan $560 \times 560 \times 560$ piksel. Citra digital sampel tanah dianalisis menggunakan perangkat lunak CTVox (Bruker Micro-CT). CTVox digunakan untuk analisis kualitatif dengan basis visualisasi 3D. Analisis citra digital untuk karakterisasi parameter struktur sampel tanah dan batuan dilakukan dengan CTAn. Parameter fisis yang dianalisis adalah derajat anisotropis, ukuran pori dan ukuran butiran tanah. Didapatkan hasil sampel tanah yang dipindai pada tegangan $100 \mathrm{kv}$ memiliki kualitas citra yang lebih baik, ditunjukan oleh lebih jelas dan jernihnya citra digital. Hasil analisis derajat anistropis, distribusi ukuran pori, distribusi ukuran butiran menunjukan bahwa sampel tanah memiliki derajat anisotropis, ukuran pori, dan ukuran butiran yang jauh lebih besar dibandingkan dengan derajat anistropis, ukuran pori dan ukuran butiran pada sampel batuan.
\end{abstract}

Kata-kata kunci: analisis citra digital ,derajat anisotropis, ukuran pori, ukuran butiran.

\begin{abstract}
Imaging technology 3D structure of porous medium is evolving rapidly with the scanner device $\mathrm{x}$-ray Micro Computed Tomography. On the research of digital image analysis was conducted of a sample of soil and rocks of the scan results with Skyscan Micro-CT 1173. Further analysis conducted on a sample of soil that is scanned by two parameters of $\mathrm{x}$-ray energy $(100 \mathrm{kV}$ and $130 \mathrm{kV})$. Subsequent analysis focuses on a comparison of the physical parameters of the soil and rock samples. Digital soil and rock samples each measuring $560 \times 560 \times 475$ pixels and $560 \times 560 \times 560$ pixels. A digital image of the soil samples were analyzed using the software CTVox (Bruker Micro-CT). CTVox is used for qualitative analysis with 3D visualization base. Digital image analysis for structure parameters characterization of samples of soil and rocks carried by CTAn. The physical parameters analyzed are the degrees anisotropis, structure thickness and structure separation. Obtained scores of soil samples scanned at 100 kv have better image quality, shown by clearer and clearer digital images. The results of anistropis degree analysis, pore size distribution, granule size distribution showed that soil samples have anisotropic degree, pore size, and grain size much larger than the anistropic degree, pore size and grain size in rock samples.
\end{abstract}

Keywords: digital image analysis, degree of anisotropis, trabecular thickness, trabecular separation. 


\section{PENDAHULUAN}

Metode pengolahan citra digital (Image processing) merupakan metode yang berkembang secara pesat dalam beberapa dekade terakhir [1]. Metode ini dinilai mampu mengkarakterisasi dan memvisualisasikan suatu objek dengan sangat baik seperti yang dilakukan Taina [2], Elliot [3] yang melakukan pengukuran kuantitatif elemen struktur tanah dengan menggunakan metode CT Scan. Selain itu metode ini juga bersifat non-destruktif artinya metode yang tidak merusak sampel berbeda dengan metode geoteknik yang memiliki sifat destruktif yang mengakibatkan sampel tidak dapat digunakan kembali. Penggunaan dari CT Scan ini biasanya diaplikasikan dalam bidang kedokteran terutama untuk mendiagnosa organ bagian dalam pada pasien. Cnudde [4] dalam penelitiannya sangat terbantu oleh kelebihan metode CT Scan guna memberikan keleluasaan pengamatan hingga empat dimensi (4D) dari perubahan struktur mikrostruktur didalamnya.

Pada penelitian ini perangkat yang digunakan untuk melakukan pemindaian terhadap sampel tanah dan batuan adalah Micro Computed Tomography Scan (Micro-CT Scan) 1173. Cara kerja perangkat ini sama dengan perangkat CT Scan dalam dunia medis. Perbedaan utama antara MicroCT dengan perangkat CT Scan dalam dunia medis adalah bahwa (ketelitian) struktur yang bisa diproyeksikan perangkat Micro-CT Scan mencapai 5 mikrometer per piksel. Adapun prinsip kerja dari perangkat ini adalah dengan memproduksi sinar-X.

Sinar-X diproduksi dalam tabung vakum sinar-X. Dalam tabung vakum sinar-X terdapat katoda (filament) dan anoda (tungsten). Jika arus dialirkan ke katoda maka akan mengakibatkan temperatur pada katoda meningkat dan elektron yang ada pada permukaan filament menjadi tidak stabil. Dengan adanya perbedaan beda potensial antara katoda dan anoda, maka elektron yang loncat pada katoda memiliki kecepatan yang sangat tinggi. Sehingga elektron pada katoda menumbuk anoda yang terdapat pada tungsten, elektron yang menumbuk tersebut membuat elektron pada tungsten yang memiliki orbital terendah akan terlempar keluar. Elektron atom tungsten yang terletak pada orbital yang lebih tinggi akan turun ke orbital yang lebih rendah dan melepaskan energi berbentuk foton. Foton inilah yang sebenarnya menjadi sinar-X [5].

Sinar- $\mathrm{X}$ yang dihasilkan oleh tabung sinar-X mengenai dan menembus objek yang dalam hal ini adalah sampel tanah dan sampel batuan, kemudian mengenai penangkap citra (detektor). Dari segi fisis, sampel tanah dan sampel batuan mempunyai kerapatan yang berbeda-beda sehingga ketika sinar-X melewati suatu objek akan mengalami atenuasi yang berbeda-beda tergantung dari bagian yang dilewatinya. Perbedaan atenuasi mengakibatkan perbedaan nilai intensitas yang ditangkap detektor dan perbedaan intensitas ini divisualisasikan sebagai citra dari sampel. Semakin besar massa jenis yang dilewati maka semakin kecil energi yang diterima oleh detektor. Atenuasi yang terjadi mengikuti aturan atenuasi eksponensial yang berasal dari pengurangan intensitas dari intensitas awal yang dipengaruhi oleh koefisien atenuasi dan panjang benda yang ditembus sinar-X.

Tujuan dari penelitian ini adalah untuk menganalisis perbandingan citra digital sampel tanah yang dipindai dengan dua parameter voltase yang berbeda yaitu sampel tanah yang dipindai dengan voltase $100 \mathrm{kV}$ dan sampel tanah yang dipindai dengan voltase $130 \mathrm{kV}$. Serta analisis berikutnya adalah menganalisis karakteristik sampel tanah dan batuan. Pada penelitian ini parameter fisis yang dianalisis adalah derajat anisotropi, ukuran butir, dan ukuran pori sampel tanah dan sampel batuan.

\section{METODE PENELITIAN}

Metode yang digunakan dalam penelitian ini adalah metode pengolahan citra digital. Penelitian ini menggunakan sampel tanah yang berukuran $560 \times 560 \times 475$ piksel dan sampel batuan yang berukuran $560 \times 560 \times 560$ piksel. Kemudian sampel tanah dan batuan dipindai menggunakan perangkat MicroCT SkyScan 1173 yang dapat dilihat pada GAMBAR 1. Selanjutnya sampel tanah dan sampel batuan ditempatkan pada sebuah chamber seperti pada GAMBAR 1 (b). Sampel tanah dan batuan yang telah ditempatkan pada sebuah chamber dimasukan kedalam perangkat Micro-CT Scan seperti pada GAMBAR 1 (a) untuk dilakukan pemindaian sampel.

Pemindaian sampel tanah dilakukan sebanyak 2 kali yang pertama dengan voltase $100 \mathrm{kv}$ dan yang kedua dengan voltase $130 \mathrm{kv}$. Sedangkan pemindaian untuk sampel batuan hanya dilakukan 
dengan voltase $130 \mathrm{kv}$. Selain itu parameter-parameter lain seperti arus (dalam $\mu \mathrm{A})$, lama paparan (time exposure dalam ms), penapis sinar-X (filter) dibuat bernilai sama. Pada tahap ini sampel tanah dan sampel batuan siap untuk diuji.

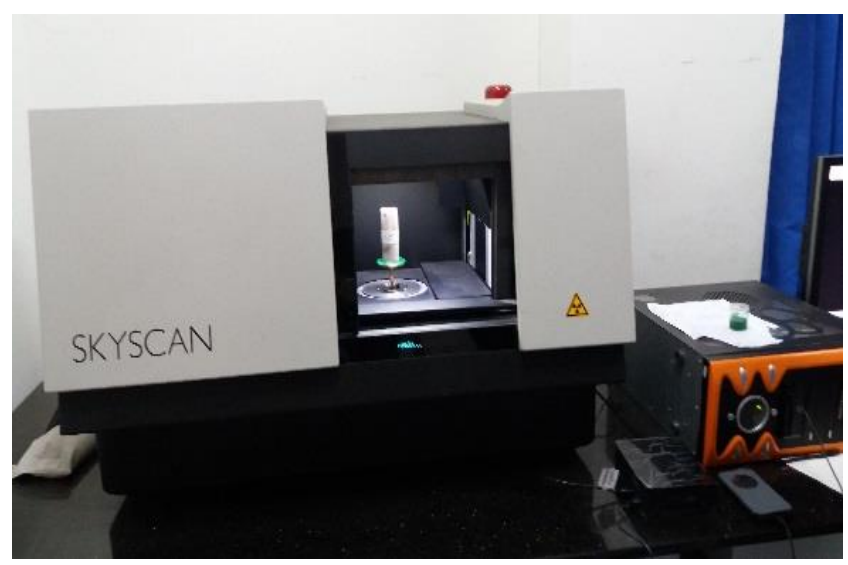

(a)

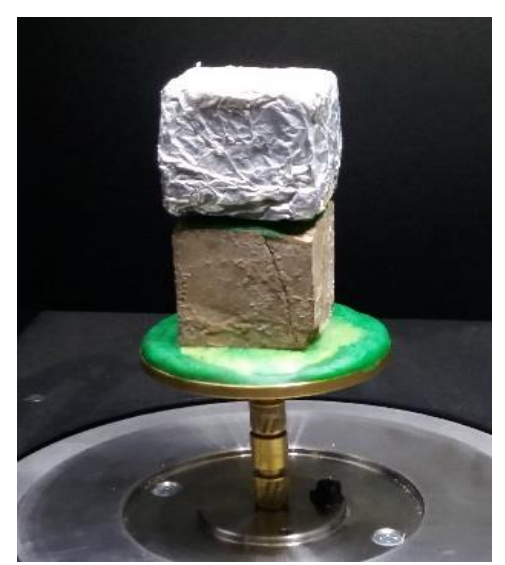

(b)

GAMBAR 1 (a) Perangkat Micro-CT Scanner SkyScan 1173, (b) sampel tanah dan batuan.

Setelah dilakukan pemindaian sampel tanah dan sampel batuan didapatkan data sekumpulan citra digital yang disebut citra proyeksi (projection image ). Citra ini memiliki format data .TIFF, 16 bit. Citra digital skala keabuan tersebut (grayscale image) memiliki rentang derajat keabuan dari 0 hingga 65.535 skala. Selanjutnya kumpulan citra proyeksi hasil pemindaian sampel tanah dan sampel batuan direkonstruksi menggunakan perangkat lunak NRecon (dapat dilihat pada GAMBAR 2).

Rekonstruksi adalah proses pengirisian cross-section bayangan hasil pemindaian menjadi citra film tipis (thin section image) per 1 piksel yang diiris pada arah sumbu $z$. Adapun hasil yang didapatkan pada tahap rekonstruksi berupa citra skala keabuan dengan format data BMP, 8 bit (dapat dilihat pada GAMBAR 3).

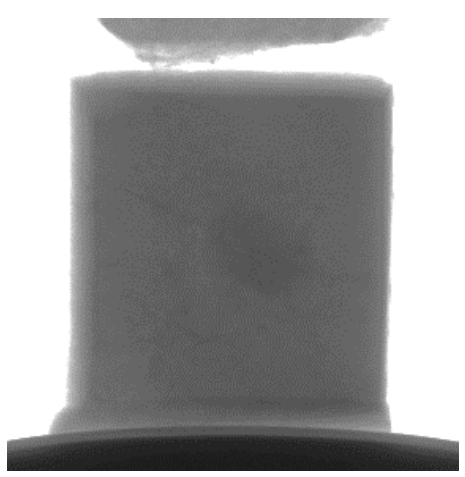

(a)

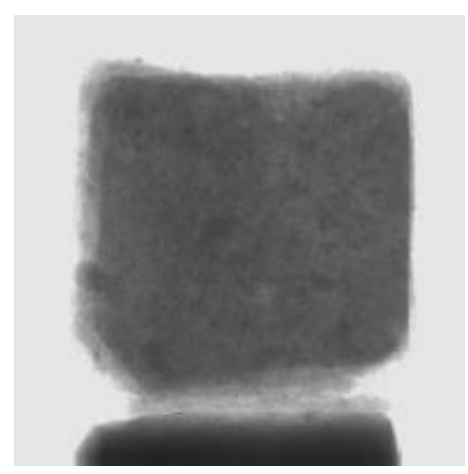

(b)

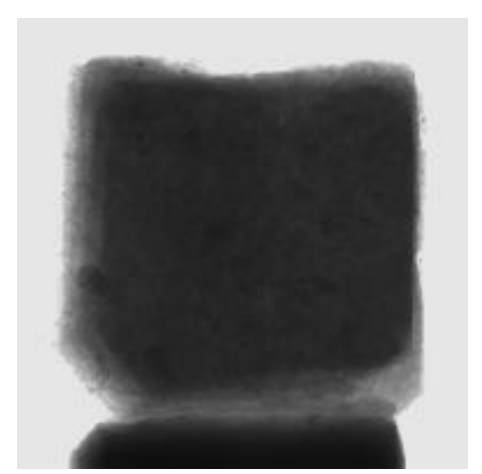

(c)

GAMBAR 2 (a) Citra digital pada proses rekonstruksi sampel batuan $130 \mathrm{kv}$, (b) Citra digital pada proses rekonstruksi sampel tanah $130 \mathrm{kv}$, (c) Citra digital pada proses rekonstruksi sampel tanah $100 \mathrm{kv}$

Citra digital hasil rekonstruksi sampel tanah dan sampel batuan kemudian diproses oleh perangkat lunak CTAn untuk dilihat parameter-parameter fisinya. Parameter fisis yang dianalisis pada penelitian ini yaitu derajat anisotropis, ukuran butiran, dan ukuran pori sampel tanah dan sampel batuan. Hal pertama yang dilakukan oleh perangkat lunak CTAn dalam menganalisis parameter fisi adalah menentukan Region Of Interest (ROI). ROI adalah pemilihan suatu daerah dari objek yang akan dianalisis lebih lanjut. Kemudian setelah menentukan ROI, langkah selanjutnya yaitu melakukan thresholding. Thresholding adalah suatu proses pembuatan citra-hitam putih (binary image) dari citra skala keabuan untuk membedakan daerah padatan dengan daerah pori sampel. 


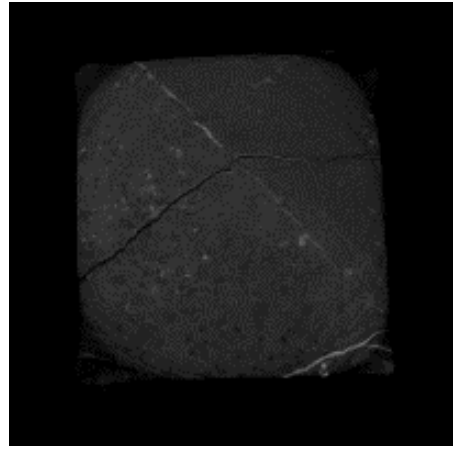

(a)

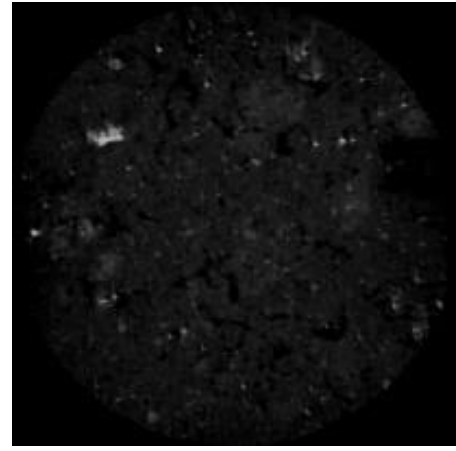

(b)

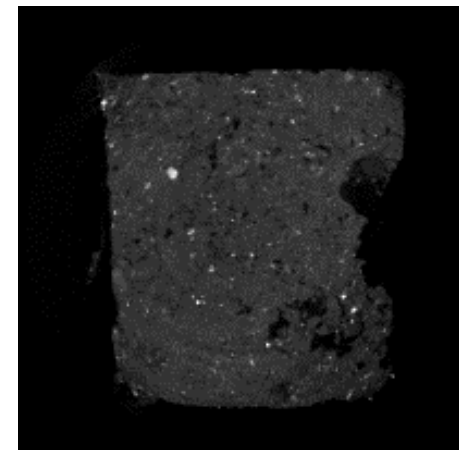

(c)

GAMBAR 3 (a) Citra digital hasil keluaran rekonstruksi sampel batuan $130 \mathrm{kv}$, (b) Citra digital hasil keluaran rekonstruksi sampel tanah $130 \mathrm{kv}$, (c) Citra digital hasil keluaran rekonstruksi sampel tanah $100 \mathrm{kv}$

Selain menggunakan perangkat lunak CTAn, citra digital hasil pemindain divisualisasikan oleh perangkat lunak CTVox. CTVox digunakan untuk analisis kualitatif dengan basis visualisasi 3D. Hasil analisis kualitatif perangkat lunak CTVox digunakan untuk membandingkan citra digital sampel tanah $130 \mathrm{kv}$ dengan $100 \mathrm{kv}$.

\section{HASIL DAN PEMBAHASAN}

Hasil dari pemrosesan dan analisis citra dari sampel yang dipindai, memberikan gambaran mengenai beberapa parameter fisis yaitu derajat anisotropis, ukuran butiran, dan ukuran pori. Adapun GAMBAR 4 merupakan grafik distribusi ukuran butiran pada masing-masing sampel tanah dan sampel batuan.

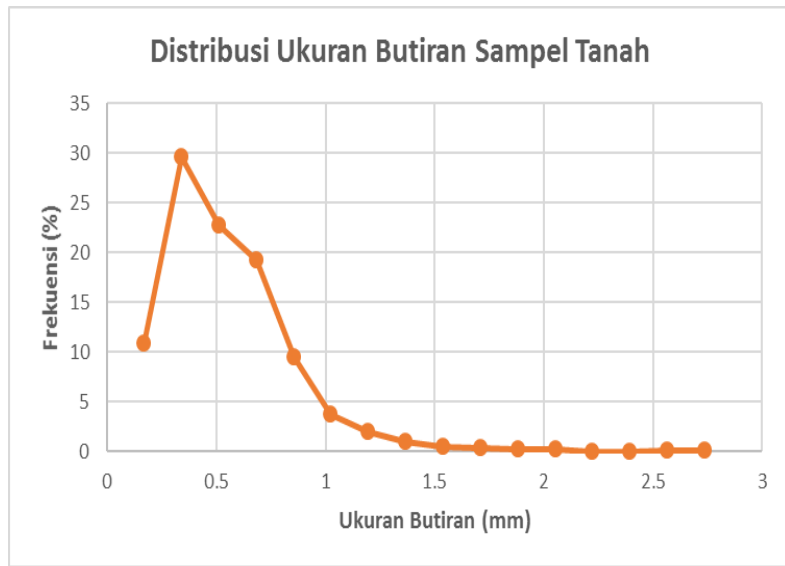

(a)

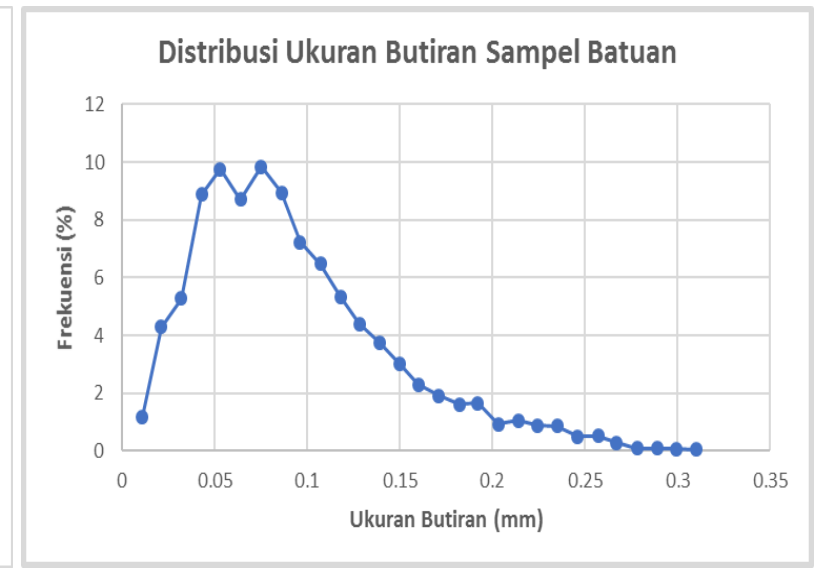

(b)

GAMBAR 4 (a) Distribusi ukuran butir sampel tanah (b) Distribusi ukuran butiran sampel batuan

Berdasarkan grafik distribusi ukuran butiran pada GAMBAR 4 dapat dilihat bahwa ukuran butiran sampel tanah memiliki frekuensi terbesar di sekitar rentang 0,25 hingga $1 \mathrm{~mm}$ sedangkan pada sampel batuan ukuran butiran yang memiliki frekuensi terbesar di sekitar rentang 0,05 hingga $0,1 \mathrm{~mm}$. Sehingga dapat disimpulkan bahwa ukuran butiran sampel tanah lebih besar dibandingkan dengan ukuran butiran sampel batuan. 


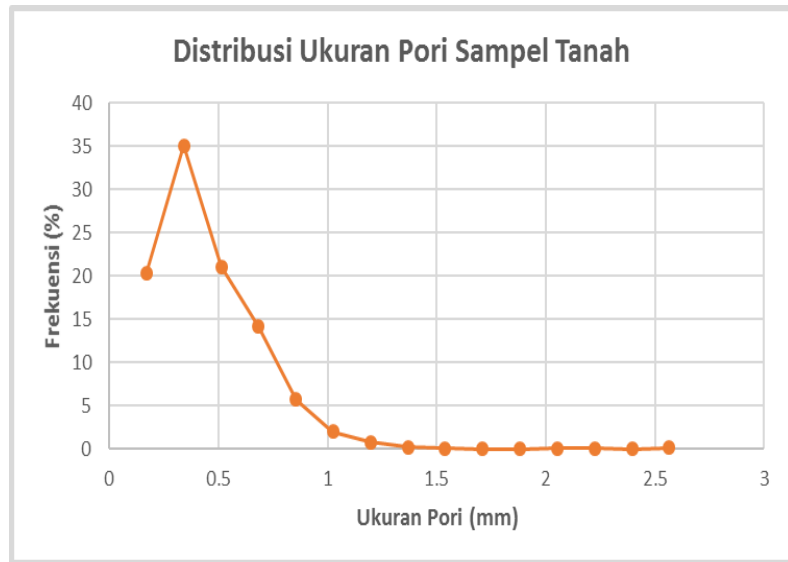

(a)

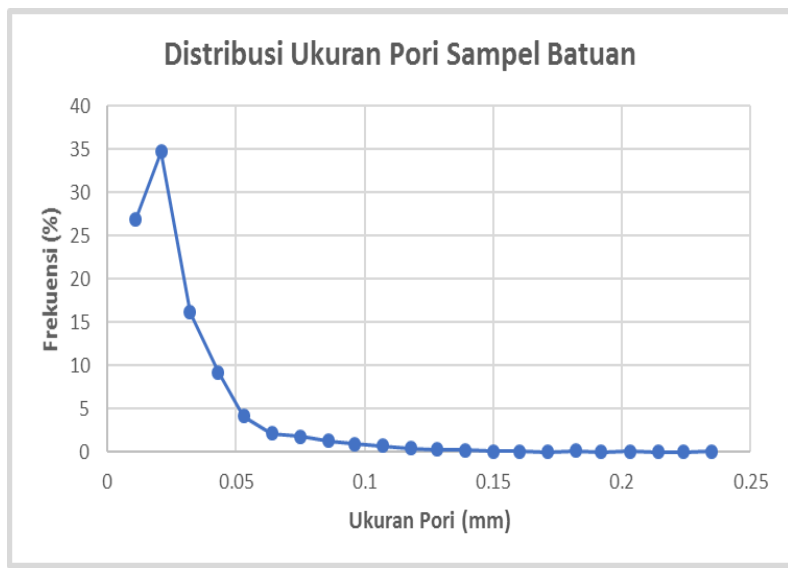

(b)

GAMBAR 5 (a) Distribusi ukuran pori sampel tanah (b) Distribusi ukuran pori sampel batuan

Berdasarkan grafik distribusi ukuran pori pada GAMBAR 5 dapat dilihat bahwa ukuran pori sampel tanah memiliki frekuensi terbesar di sekitar rentang 0,25 hingga $1 \mathrm{~mm}$ sedangkan pada sampel batuan ukuran pori yang memiliki frekuensi terbesar di sekitar rentang 0,01 hingga $0,05 \mathrm{~mm}$. Berdasarkan hal tersebut dapat disimpulkan bahwa ukuran pori sampel tanah lebih besar dibandingkan dengan ukuran butiran sampel batuan. Adapun TABEL 1 merupakan hasil analisis parameter-parameter fisis perangkat lunak CTAn.

Berdasarkan parameter -parameter fisis pada TABEL 1 dapat disimpulkan bahwa karakteristik sampel tanah memiliki derajat anisotropis, rata-rata ukuran butiran, dan rata-rata ukuran pori yang lebih besar dibandingkan sampel batuan.

TABEL 1. TABEL parameter-parameter fisis hasil perangkat lunak CTAn.

\begin{tabular}{lcc}
\hline Parameter & Sampel Tanah & Sampel Batuan \\
\hline Derajat Anisotropis (DA) & 1,50346 & 1,45846 \\
$\begin{array}{l}\text { Rata-rata ukuran Butir } \\
(\mathbf{m m})\end{array}$ & 0,55057 & 0,09354 \\
Rata-rata ukuran Pori (mm) & 0,45544 & 0,02998 \\
\hline
\end{tabular}

Berdasarkan parameter -parameter fisis pada TABEL 1 dapat disimpulkan bahwa karakteristik sampel tanah memiliki derajat anisotropis, rata-rata ukuran butiran, dan rata-rata ukuran pori yang jauh lebih besar dibandingkan sampel batuan.

Karakteristik sampel tanah juga dapat dilihat secara kualitatif yaitu dalam bentuk tampilan 3D menggunakan perangkat lunak CTVox. Analisis kualitatif ini digunakan untuk membandingkan sampel tanah yang dipindai dengan voltase $130 \mathrm{kv}$ dan $100 \mathrm{kv}$. Adapun hasil visualisasi sampel tanah dapat dilihat pada GAMBAR 6. 


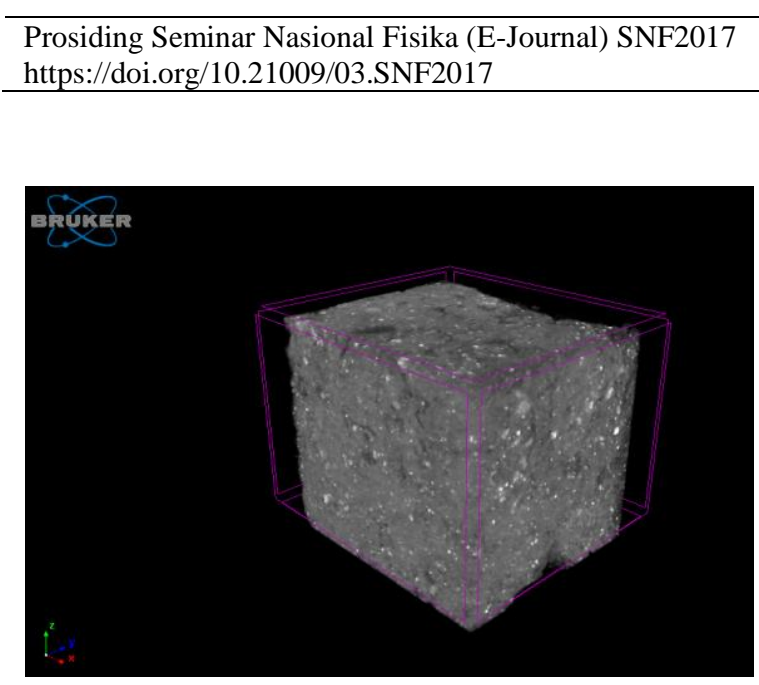

(a)

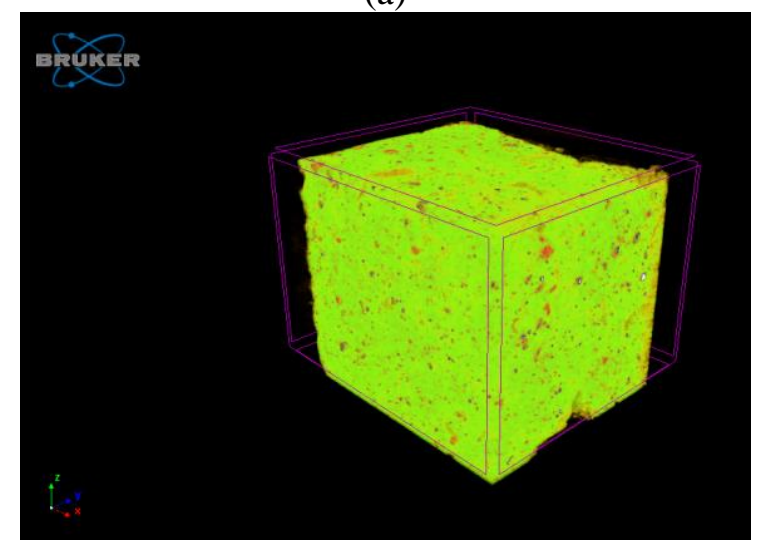

(c)

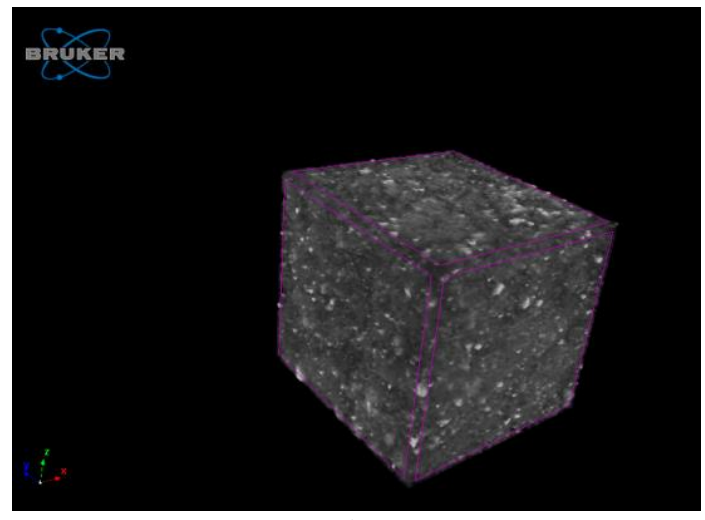

(b)

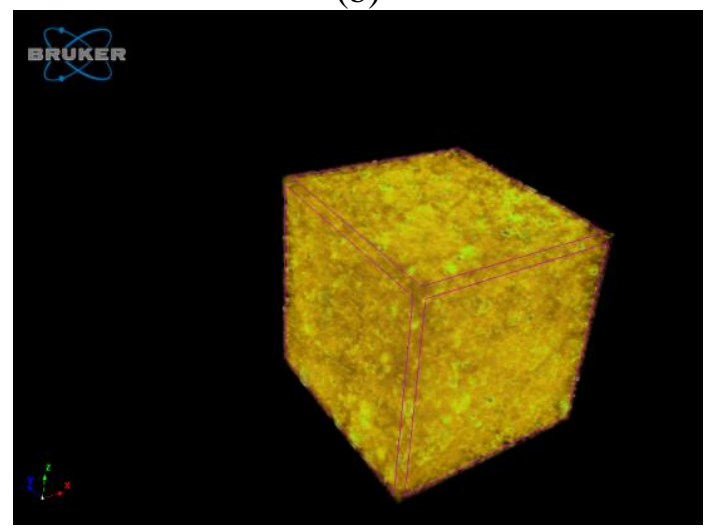

(d)

GAMBAR 6. Citra hasil perangkat lunak CTVox (a) dan (c) citra tanah voltase $100 \mathrm{kv}$, (b) dan (d) citra tanah voltase $130 \mathrm{kv}$

Berdasarkan hasil citra yang diperoleh dengan menggunakan perangkat lunak CT Vox pada GAMBAR 6. Citra tanah bervoltase $100 \mathrm{kv}$ terlihat lebih jelas dan jernih dibandingkan dengan citra tanah bervoltase $130 \mathrm{kv}$ dikarenakan tanah memiliki densitas yang tidak terlalu besar sehingga apabila digunakan voltase yang terlalu tinggi, perbedaan antara atenuasi ruang kosong dengan atenuasi objek akan terlihat sama mengakibatkan citra kurang baik. Sehingga secara tampilan citra tanah bervoltase $100 \mathrm{kv}$ akan lebih mudah untuk membedakan daerah pori dengan daerah padatan.

\section{SIMPULAN}

Hasil parameter-parameter tanah yang dianalisis secara kualitatif menunjukan bahwa sampel tanah yang dipindai pada voltase $100 \mathrm{kv}$ memiliki kualitas citra yang lebih baik dibandingkan dengan tanah yang dipindai dengan voltase $130 \mathrm{kv}$ ditunjukan oleh lebih jelas dan jernihnya gambar. Hasil analisis distribusi ukuran butiran dan ukuran pori menunjukan bahwa ukuran butiran dan ukuran pori sampel tanah jauh lebih besar dibandingkan dengan ukuran butiran dan ukuran pori sampel batuan. Disamping itu, hasil analisis parameter fisis derajat anisotropis sampel tanah pun lebih besar dibandingkan sampel batuan.

\section{UCAPAN TERIMAKASIH}

Penulis mengucapkan terima kasih kepada Firmasnyah yang telah memberikan masukan dalam penyelesaian dan penyempurnaan hasil karya ilmiah ini serta kepada laboratorium instrumentasi Institut Teknologi Bandung yang telah membantu dalam proses pemindaian sampel tanah dan batuan yang digunakan pada penelitian ini. 


\section{REFERENSI}

[1] L. J. Munkholm, R. J. Heck, B. Deen, Soil pore characteristics assessed from X-ray microCT derived images and correlations to soil friability, Geoderma, 2012, Vol 181, pp 22-29.

[2] I. A. Taina, R. J. Heck, Application of X-ray computed tomography to soil science: A literature review, Canadian Journal of Soil Science, 2008, 88(1), 1-19.

[3] T. R. Elliot, R. J. Heck, A comparison of optical and X-ray CT technique for void analysis in soil thin section, Geoderma, 2007, 141(1), 60-70.

[4] V. Cnudde, M. N. Boone, High-resolution X-ray computed tomography in geosciences: A review of the current technology and applications, Earth-Science Reviews, 2013, 123, 1-17.

[5] I. Susila, Karakterisasi Flat- Panel Detector untuk Pesawat Sinar-X Digital, PRIMA 10(2), 2013, pp. 39-50. 
